\title{
CAN CLOSE COOPERATION BETWEEN ESP/CLIL EXPERTS AND DISCIPLINARY TEACHERS IN HIGHER EDUCATION LEAD TO FOSTERING ENGLISH EDUCATION ENVIRONMENT
}

\author{
L’udmila Hurajová
}

Slovak University of Technology, Faculty of Materials Science and Technology in Trnava, Slovak Republic

\begin{abstract}
Current challenges and issues are so complex that without a close, interdisciplinary and multidisciplinary cooperation it is very difficult or even impossible to solve and find innovative approaches to them. We are living in the era of big data, artificial intelligence and also virtual reality which are changing the paradigm of all our living including education. As far as communication within multidisciplinary and multinational working teams is concerned, English has become a preferable language that is used worldwide including academia and research. In non-English speaking countries Higher Education Institutions (HEIs) have faced very similar challenge how to foster establishing English Education Environment (EEE). Most of their students speak different language and their level of English competence differs. Likewise, disciplinary teachers' (DTs') English competence and readiness to teach their courses in English vary. This contribution describes the project (Visegrad+) of HEIs from Slovakia, Hungary, Poland, Albania and Serbia, intended to study if Content and Language Integrated Learning (CLIL) and close cooperation between ESP/CLIL experts and DTs can result in effective English learning-teaching environment. The main project outcome - web platform for ESP/ CLIL and DTs communities is presented. Finally, as far as interdisciplinary teacher cooperation is concerned, some observations during COVID19 pandemic are illustrated.
\end{abstract}

Key words: English Education Environment (EEE), interdisciplinary cooperation, internationalisation of Higher Education (IoHE), CLIL in Higher Education

\section{INTRODUCTION}

The issue of the internationalisation of higher education has been resonating across the academic sector for several decades. The growing pressure of globalization has even accelerated this process across the world. The internationalisation of the higher education environment enables institutions to meet the set goals. Higher education institutions (HEIs) have been operating in different social, geopolitical or educational contexts and therefore the goals of internationalisation differ. The internationalisation of higher education is demonstrated in various forms such as: student and staff mobility, internationalisation at home, off-shore campuses, dual degree study programs, network international cooperation, project collaboration, international research centres and the others.

Submitted October $31^{\text {st }}, 2020$, accepted for publication November $25^{\text {th }}, 2020$

Corresponding author: Ludmila Hurajová. Slovak University of Technology, Faculty of Materials Science and Technology in Trnava, Slovak Republic|E-mail: ludmila.hurajova@stuba.sk 
Kolesnikov et all (2019) also describe and study the growing phenomenon - international university research ventures (IURV). HEIs also differ in their motivation to internationalize the processes. Some of the universities might be driven by revenue, others by prestige, building an international environment for sharing knowledge and experience or by diversifying the educational environment. Building an international environment in various forms also assumes a common communication base. Currently, English is the hegemonic language tool used for this purpose. It can be said that the setting of the international environment in the already mentioned areas is the same as to set up an English educational or cooperative environment. This paper focuses on internationalisation at home, where HEIs try to set up an international education environment for students whose mother tongue is not English. Fostering internationalisation at home requires dealing with the students who have applied for programs taught not in English and they do not have to be willing to study in English and be an active part of English Education Environment (EEE). Harrison (2015) states that "home students across the world are often found to resist intercultural group work and generally to avoid contact with their international peers, leading to concerns about unequal access to transformative experiences and powerful knowledge".

In Slovakia, most universities provide study programs in the Slovak language. Some medical and business study programs are offered and provided in English in the environment with real international students. In a quick survey conducted at MTF STU 3 years ago, we investigated the students' willingness to study disciplinary courses in English. Most of the students declared their natural fear of English and were more diligent to study the courses partially taught in English. Therefore, we started considering CLIL (Content and Language Integrated Language) as a potential approach for setting English Education Environment to foster the process of 'internationalisation at home' at our faculty. CLIL application into disciplinary courses requires a close cooperation with disciplinary teachers in HEIs, as ESP/CLIL experts cannot cover professional fields so deep as disciplinary teachers do. However, disciplinary teachers can be lost without any didactical and linguistic assistance of ESP/CLIL experts in delivering English education environment effectively. Using CLIL approach means to have essential knowledge how to implement its main dual principle - teaching and developing content and language at the same time. It seems that disciplinary teachers and ESP/CLIL experts are entirely dependent on close cooperation. How such cooperation can look like and if it brings the required results is the focus of investigation in one Visegrad+ project called "CLILHigher Education Teacher" (CLIL-HET) that will be described and explained in this contribution.

\section{CLIL IN HIGHER EDUCATION}

The EEE setting varies from country to country, and even from university to university. Some HEIs offer full study programs in English and require an appropriate level of language competence. Level B2 according to the Common European Framework Reference of Languages (CEFR) is the minimum for admission to these types of universities, but most of them require $\mathrm{C} 1$ level of the English language competence. Most of such HEIs are established in English-speaking countries or their offshore campuses around the world. They have enough many teachers who speak English as native users. The students applying for these types of HEIs are motivated to study in English, as these are mostly prestigious schools. Diplomas 
from these schools open up opportunities for better paid and more attractive positions on the labour market. In these case English is used as a communication tool/medium for educational process. Can CLIL foster accelerating the process of internationalisation, in other words, setting up EEE in the artificial conditions of HEIs, where most students do not speak English to the required level - so that they can study entire study programs in English? At the same time, some disciplinary teachers miss sufficient level of English as well. Last but not least, most academic staff do not have the didactic-pedagogical education needed to implement CLIL. Close interdisciplinary cooperation sounds as a solution, doesn't it?

\subsection{Dual principle of CLIL}

The above-mentioned dual principle is the most crucial principle of CLIL approach in the effectively set CLIL environment students should develop disciplinary knowledge and language competence at the same time. Historically, the first teachers who started using CLIL in their lessons were language teachers. They were those proactive professionals, who saw the potential of this approach. First pilot projects were mainly done on primary and secondary level of education. Many research studies have been conducted on CLIL and its impact on students' language improvement both in the subjects and in the language used within CLIL lessons. Other studies dealt with teachers and their trainings how to implement CLIL into lessons effectively. We could see some attempts to have a unified procedure for CLIL implementation into the education, however, as we have found it out in our ERASMUS+ project, it is not possible, as there are many variables that should be taken into account. Education systems vary around the world and even there exist many differences on regional, local, institutional levels.

\subsection{Disciplinary teachers in CLIL environment}

Although language teachers (ESP experts) seem to be pioneers in CLIL application into their lessons in higher education utilising content from specific disciplines in their classes, they usually do not have sufficient degree of knowledge in any subject that are taught by disciplinary teachers. Moreover, they naturally focus on linguistic features of language, so dual principle of CLIL is not in balance. On the other hand, disciplinary teachers are experts in their own fields, but a few of them are also experts in English didactics or CLIL approach. Setting an effective CLIL environment (in another word $\mathrm{EEE})$ requires either teachers with double degree (in discipline and in English didactics) or close cooperation between ESP/CLIL teachers and disciplinary teachers in the institutions. Contero et al. (2018) stated some uncertainty of disciplinary teachers they expressed in their study, specifically in linguistic awareness and scaffolding in CLIL lessons. They were not sure if they set the dual principle of CLIL in a perfect balance, if the language was integrated in their lessons effectively.

\subsection{Interdisciplinary cooperation}

To have dual principle of CLIL in balance close cooperation is requested. Morgado et. al (2018) studied and described "in-tandem" teaching, which can bring novelty into students' learning and also contributes to the developing teachers' teamwork, collaboration and solving problem in English. Reitbauer et al. (2018) suggest using the cognitive load theory while CLIL is implemented into education and recommended language specialists guide 
disciplinary teachers to help them accept the fact, that every teacher in some way can be a language teacher. They think "CLIL integration will become more effective and lead to better learning outcomes, since awareness of the respective teaching methodologies for content and language, as well as proper understanding of the functions of language and the human cognitive architecture." Wilkinson (2018) reflects several contributions on English as a Medium of Instruction (EMI), ESP/EAP (English for Specific Purposes, English for Academic Purposes) and CLIL/ICLHE (Integration of Content and Language in Higher Education) in his paper. He perceived collaboration between subject specialists and language teachers as "one of the more challenging aspect of course design, implementation and assessment". He also called for "explicit training in methodology of teaching content through English" and emphasized that EMI programmes reshaped teacher identity. Leshchenko et al. (2018) declare that "pure CLIL is not enough sufficient without ESP support." They highlighted two possible solution for designing an effective CLIL environment: close collaboration between content and language teachers in higher education and combination of CLIL classes with ESP classes for students.

\subsection{CLIL trainings for academic staff}

As far as teachers in higher education are concerned, most of them have no knowledge of branch didactics or general pedagogical education. Despite this fact, one of their main tasks is education. They often become good teachers after many years of practice. Regarding the need of special CLIL trainings for disciplinary teachers, we should also consider some didactics and pedagogical issues. Bucker et al. (2013) in their study about a two day seminar "Academic Teaching" for doctoral students say that "every university teacher has to come to conviction how he wants to place himself with regards to his research and teaching duties. It should be the mission statement for centres of didactics to deliver the message that neither the teaching should be neglected to strengthen research, nor that research should be abandoned in the favour of teaching."

Disciplinary teachers should have the opportunity to be educated not only in CLIL approach but also in general didactics and pedagogy while they are preparing for CLIL application into their classes. Hillyard (2011) introduced models for CLIL trainings and what should be taken into account while a CLIL course for beginner teachers is being designed.

\section{CLIL - HET PROJECT}

We have been investigating CLIL approach in different educational contexts for several years. After finishing the ERASMUS+ project called "Transnational exchange of good practice among European Educational Institutions". One of the findings was the fact, that CLIL application differs depending on the level of education, national or local education systems, school management support, teachers' willingness to implement CLIL approach and others. However, one crucial condition must be met while CLIL is being applied - following the dual principle of CLIL - setting an educational environment that supports the development of content knowledge and language competence at the same time. There is no unified methodology on how to do that. The observations of CLIL lessons were done in primary and high schools. Since the end of the project, we started considering CLIL a potential approach for enhancing English education environment in 
HEIs. The initiative for fostering the process of internationalisation using CLIL and close interdisciplinary cooperation came from ESP specialists at MTF STU, who addressed the colleagues in other countries (the Czech Republic, Hungary, Poland, Serbia and Albania) and submitted the project CLIL-Higher Education Teacher (CLIL-HET) in 2019. After approval, there was the plan to finish it till June 2020, yet due to COVID 19 pandemic it has been prolonged till June 2021. Therefore, we cannot provide any project findings in the contribution. Nevertheless, we will describe our aims, planned outcomes and features of the web platform clil-het.eu that has already been built.

\subsection{Project Aim}

The project CLIL-HET is aimed at building an online space for grouping two communities of specialists: disciplinary teachers (DTs) and ESP/CLIL experts. The space is provided within the web platform www.clil-het.eu. One of the objectives is to support close cooperation between these two communities not only on the national level but also on the international one. The international cross-institutional cooperation between DTs and between CLIL/ESP experts is fostered as well. The platform offers the space for sharing knowledge, experience and best practice in setting EEE in V4 countries and Western Balkan countries. The platform is open for the experts from all HEIs who are willing to contribute to the process of internationalisation specifically - 'internationalisation at home'.

\subsection{Project Outcomes}

The project CLIL-HET comprises three major outcomes: Open Source Digital Platform (OSDP), Didactic programme for disciplinary teachers (DP-DTs) and Identifying linguistic weaknesses (ILWs). One project event is planned with the current date in January 2021. It will be the seminar "ESP and CLIL - current drivers of HEI internationalisation" for both communities (DTs and ESP/CLIL experts).

\subsection{OSDP - web platform}

Open source digital platform (www.clil-het.eu) offers online space for DTs and ESP/ CLIL experts to collaborate locally, nationally and transnationally to foster internationalisation process of HEIs in V4 and WB (Western Balkan) countries that enables incoming and outcoming mobility to increase. The platform consists of several sections: project corner, didactic corner, research corner and community corner, all with their own features. The didactic corner is divided into two subsections that are devoted mainly to DTs. The Didactic programme for disciplinary teachers (DP-DTs) was designed to provide essential knowledge on CLIL approach, English didactics and CLIL lesson planning. The DP-DTs is the result of the close cooperation of ESP/CLIL experts from all project partners. The second subsection is the place for uploading teaching materials for CLIL activities/seminars/lectures from various disciplines. This bank of sources is being built currently. There will be a guide on how to set English education environment (EEE) to assist DTs at setting such an environment effectively.

Community corner meets the objective of building a place for the networking of two communities (DTs and ESP/CLIL experts). Each member has their profile with the information about professional specialization and can search for someone who would like to cooperate with within the communities using and setting the filter features.

Research corner offers the latest contributions to current research in the field of internationalisation of HEIs, CLIL implementation in higher education, ESP/CLIL and 
disciplinary teachers' cooperation. The monograph with the project results and some recommendations for setting EEE in higher education using CLIL will be an integral part of the Research corner. This corner also consists of the items of the project outcome ILWs.

\subsection{ILWs - Identifying Linguistic Weaknesses}

The process of delivering the project outcome ILWs has been started. ESP/CLIL experts involved in the project have designed the language diagnostic test for DTs, and the questionnaire has been uploaded into the web platform. DTs, at all partner universities, have been addressed to go through the test and the questionnaire to collect the data on their readiness for setting EEE from a language perspective and also their perceptions on teaching in English. CLIL lessons/activities are being planned by the DTs who participate in the project. It is being done with the assistance of CLIP/ESP experts. The CLIL lessons/activities will be observed during the current term either in an online or offline environment according to the regulations that are relevant to the COVID 19 pandemic situations in each partner institution. The data gained from the questionnaire, the language diagnostic test and the observations will be processed and interpreted in the findings report which will be a part of the research section in the OSDP. The results achieved from the ILWs outcome are planned to be used for the next international project with the aim at designing linguistic, supportive programme for DTs and for students to soften their natural fear from teaching and being taught in English and at the same time to assist them in improving their language competence.

\section{CONCLUSION}

Enhancing internationalisation process in HEIs in which there are mostly non-English speaking students and academic staff, is based on setting EEE effectively utilising human sources with their language competence and their willingness to participate in this process. CLIL /ICLHE seems to be an appropriate approach to start the process of EEE settings. The main stakeholders in the process come from two communities: ESP teachers and disciplinary teachers. Their close cooperation can soften the doubts of disciplinary teachers in their linguistic readiness for setting EEE. It can enable them to understand essentials of English didactics. The interdisciplinary cooperation can flourish if there are also some CLIL experts who can design courses for disciplinary teachers to assist them to set EEE effectively. Mutual cooperation can bring benefits not only for those experts involved in setting EEE but also for students, who can study and develop English in ESP courses and in CLIL classes from various disciplines. Alhasani and Stojković (2017) believe that ESP and CLIL classes, these "two English teaching approaches can complete one-another and finally guarantee effective and rapid English language acquisition tailored for all disciplines without further cramming the university curricula."

CLIL/ICLHE is seen as not only a gate for enhancing the internationalisation of HEIs, but also for managing education in multilingual environment. (Mammadova, 2016; Wilkinson, 2018). Cooperation and shift in teachers' roles in CLIL environment are the necessities (Hurajová \& Luprichova, 2015; Hurajová, 2015; Hurajová, 2016). 
ACKNOWLEDGEMENTS: This contribution is published as a partial product of the international project Visegrad+ 21910035 CLIL - Higher Education Teacher (CLIL-HET). The Visegrad Fund supports for the production of this publication does not constitute an endorsement of the contents which reflects the views only of the author, and the Fund cannot be held responsible for any use which may be made of the information contained therein.

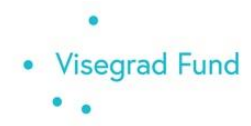

\section{REFERENCES}

Contero, Candela; Zayas, Francisco; Luis, Jose and Tirado, Arco. Addressing CLIL Lecturers Needs: Reflections on specific Methodological Training. Porta Linguarum. (2018) ISSN: $1697-7467$

Mammadova, Jamala I. Feasibility of CLIL Implementation in Education System of Azerbaijan: Attitude towards CLIL and the English Language in Higher Educational Institutions. International Journal of English Linguistics, Vol.6, No. 5., 188-200, (2016) doi: 10.5539/ijel.v6n5p188

Hurajová, Ludmila. Via International Cooperation towards CLIL Teacher Competence Enhancement. In Šimková, Z and Sorádová, D.(eds). LLCE2016: Súčasné výzvy vo vyučovani jazykov: Ako d'alej? Nitra:SlovakEdu. (2016) ISBN 978-80-89864-00-3 (76-84)

Hurajová, L'udmila and Luprichová, Jana. Being a CLIL teacher. DOI: 10.17846/CLIL. 2015.99-11 in Pokrivčáková, S. et al. (2015). CLIL in Foreign Language Education:etextbook for foreign language teachers. Nitra: Constantine the Philosopher University. $282 \mathrm{~s}$.

Hurajová, L’udmila. Tertiary CLIL. DOI: 10.17846/CLIL.2015.85-98 in Pokrivčáková, S. et al. (2015). CLIL in Foreign Language Education:e-textbook for foreign language teachers. Nitra: Constantine the Philosopher University.282s.

Morgado, Margarida; Gaspar, Marcelo Calvete and Régio, Mónica. Interdisciplinarity and coolaboration in Higher Education Engineering courses: lean thinking applied to teaching and learning. Journal of Education Culture and Society, No. 2, 179-186, (2018) doi: 10.15503/jecs20182.179.186

Reitbauer, Margit; Furstenber, Ulla; Kletzenbauer, Petra and Marko, Karoline. Towards a cognitive-linguistic turn in CLIL: Unfolding Integration. LACLIL, 11 (1), 87-107. (2018) doi: 10.5294/laclil.2018.11.1.5.

Leschenko, Maria; lavrsch, Yuliana and halatsyn, Kateryna. The role of content and Language integrated learning at Ukrainian and Polish educational systems: challenges and implications. Advanced Education. Issue 9, 17 - 25. (2018) doi: 10.20535/2410-8286.133409

Bucker, Meike; Borowski, Esther; Vossen, René and Jeschke, Sabina. How to prepare Academic staff for their new rolw as university teachers? Welcome to the seminar "Academic Teaching". Proceedings of the $7^{\text {th }}$ International Academic Conference. International Institute of Social and Economic Sciences (IISES). 2013. Reprint by Springer International Publishing Switzerland. 231-254. (2014) doi: 10.1007/978-3319-08816-7_19 
Alhasani, Mirela and Stojkovič, Nadežda. Searching for the golden average between ESP and CLIL. The Journal of teaching English for specific and Academic purposes. Vol.5, No.2, 397-412, (2017) doi: 10.22190/JTESAP1702397A

Harrison, Neil. Practice, problems and power in ínternationalisation at home': critical reflections on recent research evidence. Teaching in Higher Education. Volume 20, Issue 4, 412-430. (2015)

Wilkinson, Robert. Content and language integration at universities? Collaborative reflections. International Journal of Bilingual Education and Bilingualism. Vol. 21 No.5, 607-615, (2018) doi: 10.1080/13670050.2018.1491948

Kolesnikov, Sergey; Yin Li, Seokkyun Woo; Shapira, Philip and Youtie, Jan. Mapping the emergence of international university research ventures. Springer Science+ Business Media, LLC, part of Springer Nature J Technol Transf (2019) 44: 11341162 https://doi.org/10.1007/s10961-017-9640-6

Hillyard, Susan. First steps in CLIL: Training the teachers. LACLIL. Issue 4 (2), 1-12. (2011) doi: 10:5294/laclil.2011.4.2.1 